\title{
Research on Feature Extraction and Evaluation Methods of Successful Design Innovation Entrepreneurship Projects
}

\author{
Huabin Wang ${ }^{1, *}$ Yitong Liu ${ }^{1}$ \\ ${ }^{1}$ Design school, South China University of Technology, Guangzhou, Guangdong, China \\ *Corresponding author. Email: hbwang@scut.edu.cn
}

\begin{abstract}
This paper is aiming at extracting the characteristics of innovative entrepreneurship projects in the field of design, discussing evaluation system of successful entrepreneurship projects, finding the way to success of design entrepreneurship, and providing reference for entrepreneurs. Taking the crowdfunding platform as an example, the method used is analyzing a large number of successful cases of innovative entrepreneurship projects from multiple perspectives, discussing the criteria for project success, and deducting the evaluation system. According to the feature extraction and opportunity identification of successful entrepreneurial projects, it can effectively provide a theoretical basis for prospective entrepreneurs. It has a certain guiding significance for the personnel involved in innovative entrepreneurship to analyze the successful methods and field distribution of design projects and establishing an evaluation method.
\end{abstract}

Keywords: design, innovation, entrepreneurship, crowdfunding

\section{INTRODUCTION}

Innovation, the driving force for the adjustment and optimization of the national economic structure, is the core influence of the country's overall development. Accelerating the integration of cultural creativity, design services and related industries, and promoting the rise of China's industries to higher place at the global value chain are already the established policies of China's national industry. Based on this background, this study aims to extract the characteristics of successful design opportunities through the analysis focus on some successful design innovation and entrepreneurial projects, and then summarize a set of effective evaluation methods for design entrepreneurs and educators who are exploring their startup path.

\section{OVERVIEW OF CURRENT STATUS OF INNOVATION ENTREPRENEURSHIP}

In recent years, the government has introduced a number of policies to encourage innovation and entrepreneurship. The executive meeting of the State Council held on April 25, 2018 decided to introduce 7 additional tax reduction measures to support innovative undertaking and the development of small enterprises. The outline of Guangdong-Hong Kong-Macao Greater

*Fund: Supported by the Humanities and Social Sciences Research Program of the Ministry of Education (20YJA760079.2)
Bay Area development plan highlights the strong economic strength and broad market opportunities of the Guangdong-Hong Kong-Macao Greater Bay Area, places technological innovation in an important position of the regional development strategy, and proposes the advice of promoting industrial design and cultural creative industries[1]. Driven by the tide of innovation and entrepreneurship, the army of entrepreneurs is also growing. In response to national policies, domestic colleges and universities actively launched innovation and entrepreneurship education courses for college students, established various entrepreneurship training camps and entrepreneurship incubation bases, and encouraged college students to join the team of independent entrepreneurship. Various entrepreneurial competitions such as "Internet + " have attracted a large number of young entrepreneurs to participate, which provides them with good display platform.

However, according to the 2018 China University Student Employment Report [2], the proportion of college students starting a business has been relatively stable over the past three years, but the overall survival rate of these entrepreneurship is low. Only less than half of them continue the businesses three years after graduation. The same question applies to many other self-employed entrepreneurs. Facing the fierce competition of entrepreneurial market, the shortcomings of failed projects are mainly reflected in: (1) Creativity is not mature enough, it is difficult for 
ideas to land in the market; (2) Lack of market experience, lack of in-depth understanding of business operation mechanisms and enterprise management methods; (3) Shortage of funds makes it difficult to undertake project operations, etc. Therefore, the analysis of the structure of the entrepreneurial market and the extraction of the experience of successful project models can help entrepreneurs improve their own innovative entrepreneurial programs and lay a solid foundation for entrepreneurial practice.

\section{Crowdfunding PlatForm - A STEPPING STONE FOR DESIGN AND INNOVATION STARTUP PROJECT}

Funding is the most important and unavoidable problem for entrepreneurs among many entrepreneurial considerations. Especially for college students with flexible thinking pattern and diverse ideas but lack of social foundation, start-up capital is the first obstacle to success for most of them. The low threshold of crowdfunding platform is the first stepping stone to the success of many entrepreneurs. Through the power of the public, their creative ideas and technical capabilities are transformed into actual productivity, which provides more possibilities for social development and technological progress. It is an important boost for achieving mass innovation.

Through online crowdfunding platform, project sponsors attract the public to provide funds to support their innovation and entrepreneurship by promising a certain return, so as to realize a win-win situation among the entrepreneurs, the public and the platform. This emerging Internet financing mode is called crowdfunding[3]. Typical types of crowdfunding models include rewards, donations, and equity[4]. At present, most crowdfunding platforms in china operate as reward-based crowdfunding. On crowdfunding platforms such as JD.com and Taobao, many entrepreneurs raise funds and return products through Internet channels, which is to some extent equivalent to the pre-order model. The amount of investment is more divided by gradients. Investors can choose the amount of support and return commodities according to their personal wishes. The larger the amount of investment, the more products will be returned after the project is successful. The original meaning of crowdfunding is to optimize the allocation of social resources with the help of emerging Internet technology to fill the gap in existing capital market of the service for start-ups[5]

\section{A. Data of design project on Taobao crowdfunding platform}

Compared with the profit model of foreign Kickstarter and other crowdfunding platforms deducting points from funds, the free commitment of Taobao crowdfunding and the large number of user groups have undoubtedly attracted the attention of many entrepreneurs. The free strategy of Taobao Crowdfunding is to raise funds, wisdom and products to enrich the innovation ecology of Alibaba[6], which is also a great opportunity for entrepreneurs to find support and get benefits.

Taobao crowdfunding platform focuses on several major modules such as audiovisual, public welfare, books, entertainment, technology, design, animation, games, food, etc. According to the statistics on official website, as of March 2019, 10,975 projects have participated in crowdfunding, among which technology, cuisine and design projects occupy the main positions, accounting for $31 \%, 25.7 \%$ and $22.3 \%$ of the total number of crowdfunding projects respectively. The specific project distribution is shown in "Table I".

TABLE I. TAOBAO CROWDFUNDING PROJECT CATEGORY DISTRIBUTION

\begin{tabular}{|c|c|c|c|c|c|c|c|c|c|c|}
\hline Classification & Technology & Food & Design & Cartoon & Entertainment & Public Welfare & Audiovisual & Books & Games & Others \\
\hline Amount & 3404 & 2824 & 2451 & 622 & 423 & 397 & 349 & 96 & 54 & 355 \\
\hline Percentage (\%) & 31 & 25.7 & 22.3 & 5.7 & 3.9 & 3.6 & 3.2 & 0.9 & 0.5 & 3.2 \\
\hline
\end{tabular}

By the time mentioned above, the most popular crowdfunding products of the platform and their crowdfunding data are as follows ("Table II"):

TABLE II. THE HOTTEST PRODUCTS TAOBAO CROWDFUNDING

\begin{tabular}{|c|l|l|l|l|l|}
\hline & \multicolumn{1}{|c|}{ Products } & \multicolumn{1}{c|}{$\begin{array}{c}\text { Cumulative } \\
\text { Amount(yuan) }\end{array}$} & $\begin{array}{c}\text { Number of } \\
\text { people }\end{array}$ & $\begin{array}{c}\text { Achievement } \\
\text { rate }\end{array}$ & $\begin{array}{c}\text { Fundraising amount per } \\
\text { capita(yuan) }\end{array}$ \\
\hline $\begin{array}{c}\text { The largest number of } \\
\text { supporters }\end{array}$ & $\begin{array}{c}\text { A deodorant that } \\
\text { purifies the air }\end{array}$ & 2324600.0 & 41280 & $4649 \%$ & $15.8-60.0$ \\
\hline $\begin{array}{c}\text { The highest amount has } \\
\text { been raised }\end{array}$ & $\begin{array}{c}\text { Baymax children's } \\
\text { air purifier }\end{array}$ & 12173795.0 & 1573 & $12173 \%$ & $1099.0-109000.0$ \\
\hline $\begin{array}{c}\text { The highest achievement } \\
\text { rate }\end{array}$ & $\begin{array}{c}\text { Baymax children's } \\
\text { air purifier }\end{array}$ & 12173795.0 & 1573 & $12173 \%$ & $1099.0-109000.0$ \\
\hline
\end{tabular}


B. The data of design project on JD.com and overseas crowdfunding platform

As another e-commerce giant, Jingdong Crowdfunding official website shows that since the establishment of its platform, it has raised a total amount of 7.05233 million yuan. The maximum amount raised for a single item is 12.053 million, and the maximum number of individual supporters for a single item is 374,000 . ("Table III")

TABLE III. JINGDONG CROWDFUNDING PROJECT CATEGORY DISTRIBUTION

\begin{tabular}{|c|l|l|l|l|l|l|l|l|}
\hline Classification & Technology & Design & Food & Home Appliances & Entertainment & Culture & Public Welfare & Others \\
\hline Amount & 7229 & 4377 & 1871 & 1120 & 959 & 713 & 630 & 2670 \\
\hline Percentage (\%) & 37 & 22.4 & 9.6 & 5.7 & 4.9 & 3.6 & 3.2 \\
\hline
\end{tabular}

As the origin of crowdfunding activities, the American website Kickstarter divides crowdfunding projects into art, comics and illustrations, design and technology, movies, food and crafts, games, music, publishing and other categories. The official website statistics shows that the total number of crowdfunding projects on the website is 433,913 , of which 35,824 are design projects, accounting for $8.3 \%$ of the total number of projects.

\section{Distribution of successful projects}

From the survey data of domestic mainstream crowdfunding platforms, it can be seen that technology and design crowdfunding projects account for more

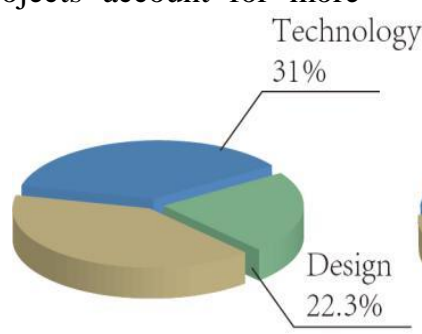

Taobao crowdfunding than half of the total number of projects together, which are the most interesting development area for entrepreneurs and the vane of social and enterprise development. Technology-based crowdfunding products are mainly composed of innovative smart products, covering household items such as fingerprint door locks, air purifiers, water purifiers; smart wearable products, such as headphones, sports bracelet; medical care products, such as massage instrument, moxibustion instrument; smart transportation, such as balance car, driving recorder, etc. In addition to living electronic products and household items, design crowdfunding products also contain a certain amount of cultural creative design products. ("Fig. 1")

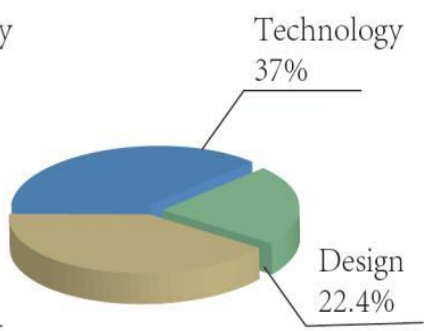

JD crowdfunding

Fig. 1. The percentage of technology and design projects on Taobao and Jingdong crowdfunding platform.

However, most technological innovation products are also blessed with cultural creativity and design. The technical factor of a product depends on technological innovation, and the shape factor of a product depends on cultural creativity[7]. Sorting out cultural resources and improving design and marketing ability of cultural and creative products are important practices for the development of China's cultural and creative industry, as well as important ways for entrepreneurs to grasp market opportunities and realize their own value.

\section{CHARACTERISTIC ANALYSIS OF OPPORTUNITY IDENTIFICATION ON SUCCESSFUL PROJECTS}

How to analyze market conditions and grasp entrepreneurial opportunities is the first challenge faced by start-ups on the way to success, and it also decides the direction and fate of entrepreneurial projects. By analyzing and summarizing the characteristics of existing successful projects in the entrepreneurial market, it can help entrepreneurs identify success opportunities more accurately and then improve their entrepreneurial concepts.

\section{A. Aiming at the market for life needs}

As the necessity of survival, life products with rigid demand have continued to expand its market with the development of economy and society, the progress of science and technology and the changes of living environment. How to seek inspiration from life and turn innovative ideas into suitable business opportunities is a topic that entrepreneurs always enjoy. At the same time, looking for defects in existing products, discovering users' pain points, optimizing and improving design on the basis of the original products, or tapping user needs 
and market vacancies to exploring new product markets, all of these can bring a lot of potential market opportunities.

Environmental issues have been a hot topic in recent years, and air purification products are very popular in the household product market. Compared with the heavy floor-mounted air purifier, in recent years, air purification products are moving toward portable or combined with other household products. For example, a product that combines an air purifier with soilless cultivated plants has achieved a success rate of nearly $400 \%$ on the Taobao crowdfunding platform, and another portable mini purifier has also completed crowdfunding with a high success rate. ("Table IV")

TABLE IV. THE CROWDFUNDING DATA OF CHENDAXIA AIR PURIFIER [8]

\begin{tabular}{|l|l|l|l|l|l|}
\hline $\begin{array}{c}\text { Dust hero } \\
\text { air purifier }\end{array}$ & $\begin{array}{c}\text { Cumulative } \\
\text { amount(yuan) }\end{array}$ & $\begin{array}{c}\text { The number of } \\
\text { participants }\end{array}$ & $\begin{array}{c}\text { Achievement } \\
\text { rate (\%) }\end{array}$ & $\begin{array}{c}\text { Unit price } \\
\text { (yuan) }\end{array}$ & \multicolumn{1}{c|}{ Features } \\
\hline & 399703 & 1337 & 399 & $\begin{array}{l}\text { Decomposition } \\
\text { graphene and activated } \\
\text { carbon }\end{array}$ \\
\hline
\end{tabular}

\section{B. Staying in familiar territory}

When entrepreneurs are faced with the choice of entrepreneurial field, they usually fall into the dilemma of choosing a field of interest or a familiar one. In early days of starting a business, choosing a field that you are familiar with means that you do not need to spend extra effort to understand new technologies and new markets, which can save time and costs and avoids unnecessary detours.

Iflytek, a national backbone enterprise engaged in the intelligent voice industry, is founded by Liu Qingfeng, a doctoral student at the University of Science and Technology of China. He was engaged in core technology research such as speech recognition during university and made many key technological innovations. He led his student team to establish Iflytek and successfully went public in 2008. Therefore, talents have unique technical advantages when engaging in entrepreneurship of their own area of expertise. Their professional qualities and market sensitivity can help them identify market opportunities and vacancies sharply, thereby providing better opportunities and directions.

\section{Making good use of cross-border resource integration}

Under the fierce market competition in today's society, no matter the research and development of new technology, the expansion of new markets, the sales and service of new products or the innovation of organizational structure, all of them are inseparable from the intersection and integration of different disciplines and knowledge[9]. Therefore, many enterprises choose to expand the market by means of cross-border resource integration to increase their own competitive advantages. As team boundaries are constantly broken and team activities become increasingly open, the acquisition and application of heterogeneous knowledge from the outside can effectively promote enterprise innovation[10].

As the famous sword in ancient China and the representative of traditional weapons, Longquan sword is also one of the treasures of traditional Chinese arts and crafts. The Longquan sword forging technique, rated as a national intangible cultural heritage, still attracts a group of consumers who are keen on traditional craftsmanship in the modern market. Quanzihao is a brand mainly engaged in the production of traditional Chinese sword craftsmanship. While studying the traditional forging skills, this brand is also committed to promoting the combination of creativity and inheritance. Through cross-border cooperation, Quanzihao forged a series of hand-made Tang swords for the remastered classic TV series "The Eagle Shooting Heroes", which accumulated 870415 yuan support fund on Taobao crowdfunding platform, achieving a huge success rate of $1740 \%$. While gaining huge profits, it used the power of the film and TV platform to push the traditional Chinese sword-making art to a broader market, realizing its original intention of popularizing art. ("Table V") 
TABLE V. THE CROWDFUNDING DATA OF QUAN ZIHAO COOPERATION PRODUCT[8]

\begin{tabular}{|c|c|c|c|c|c|c|}
\hline $\begin{array}{l}\text { Quanzihao } \\
\text { Hero Sword }\end{array}$ & $\begin{array}{c}\text { Cumulative } \\
\text { amount(yuan) }\end{array}$ & $\begin{array}{c}\text { The number of } \\
\text { participants }\end{array}$ & $\begin{array}{l}\text { Achievement } \\
\text { rate (\%) }\end{array}$ & Unit price(yuan) & $\begin{array}{c}\text { Brand } \\
\text { cooperation }\end{array}$ & $\begin{array}{c}\text { Main } \\
\text { selling point }\end{array}$ \\
\hline 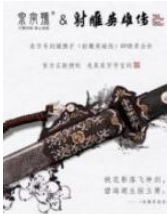 & 870415 & 585 & 1740 & $399-5999$ & $\begin{array}{l}\text { TV series } \\
\text { "The Eagle } \\
\text { Shooting } \\
\text { Heroes" }\end{array}$ & $\begin{array}{l}\text { Traditional sword- } \\
\text { making skills in } \\
\text { cooperation with well- } \\
\text { known TV series }\end{array}$ \\
\hline
\end{tabular}

D. Grasping the high-end originality market and the effect of long-tail theory

Anderson's long-tail theory believes that under certain market conditions, the market share of commodities with low demand and sales volume is equivalent to or even greater than that of mainstream products[11].

The Yimeng Yumsun chair, which has a $672 \%$ completion rate on the Taobao crowdfunding platform, its design focuses on original, high-quality and comfortable product experiences to create high-end furniture - the new Chinese-style rosewood rocking chair. The product aims at high-end market, conveys the aesthetics of traditional Chinese furniture, satisfies the user experience based on ergonomics, and also evokes people's emotional memories of rocking chairs, families and old life. This product was only supported by 135 users on the crowdfunding platform, but due to its higher unit price of 4,980 yuan, the total amount of support still stands out among many crowdfunding products. ("Table VI")

TABLE VI. THE CROWDFUNDING DATA OF YIMENG CHAIR[8]

\begin{tabular}{|c|l|l|l|l|l|l|}
\hline Yimeng chair & $\begin{array}{c}\text { Cumulative } \\
\text { amount(yuan) }\end{array}$ & $\begin{array}{c}\text { The number of } \\
\text { participants }\end{array}$ & $\begin{array}{c}\text { Achievement } \\
\text { rate (\%) }\end{array}$ & $\begin{array}{c}\text { Unit } \\
\text { price(yuan) }\end{array}$ & $\begin{array}{c}\text { Basics of } \\
\text { design }\end{array}$ & $\begin{array}{c}\text { Main } \\
\text { selling point }\end{array}$ \\
\hline & & & & & & \\
\hline
\end{tabular}

\section{E. Being based on cultural creative products}

Among many design crowdfunding projects, cultural and creative products occupy an important position among them. Quanzihao, Bronze Master and other traditional crafts production team gathered skilled and experienced craftsmen and young designers graduated from famous art schools. Through the exploration of traditional skills and the development and innovation of cultural connotation, they give traditional arts and crafts a new era significance from the perspective of modern culture. Such cultural and creative products have repeatedly break Taobao's crowdfunding record, allowing countless people turning their attention to cultural and creative market again. Therefore, using traditional cultural symbols and transforming them into modern commercial products, fully discovering and using cultural resources, and successfully adapting to the market are still one of the directions that entrepreneurs strive for. ("Table VII") 
TABLE VII. THE CROWDFUNDING DATA OF TONGSHIFU SERIES PRODUCTS [8]

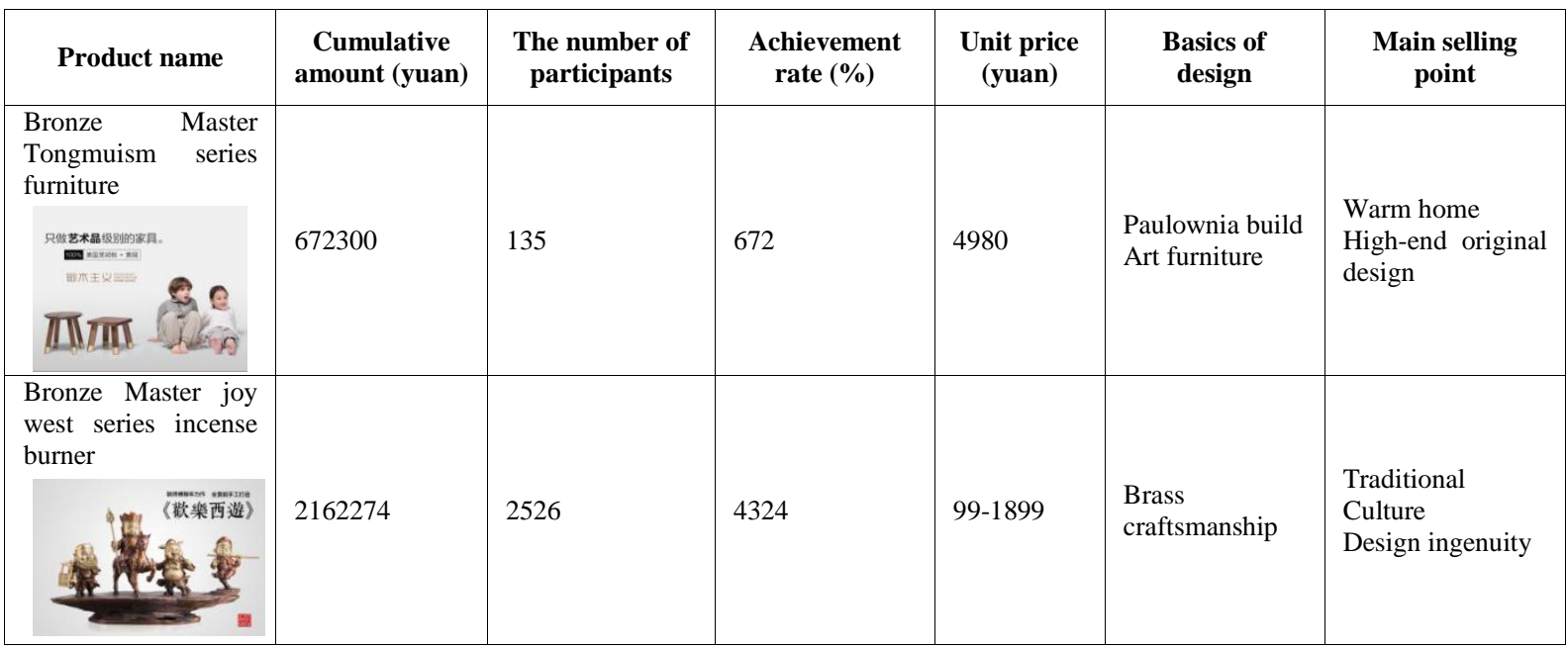

\section{Evaluation METHOD}

\section{A. Criteria for successful projects}

The meaning of success is to obtain expected result, and the success of projects means that the project reaches expected cost, profit, capital value, and meets expected ratio. Regarding to the criteria for project success, Oilsen puts forward time, cost and quality as the criteria for project success [12]. Bedell believes that while the project's success meets the above three elements, whether the customer is satisfied is also an important consideration[13]. Baker expanded customer satisfaction to project-related personnel satisfaction[14], including customers and project teams. In the early stage of a project, team members can divide success criteria according to expected value of the project, such as successful, very successful, considerably successful and extremely successful, and set expected target grade index, so as to judge the project value in a better way.

\section{B. The proposal of evaluation index}

Generally, the criteria for project success can be defined as follows: to deliver the right product or service, in the right form, at the right time, with the right quality and cost, at the right place, to the right users, to achieve the right customer satisfaction, and to obtain the right revenue.

While among crowdfunding platforms, evaluation criteria mainly focus on the number of supporters, the total amount of funds raised, and the target achievement rate. Due to the different market positioning and unit price of crowdfunding commodities, the cumulative number of supporters and accumulated funds cannot be used as the final judging criteria for the project. Whether the project achieves expected fund raising rate should be judged from the perspective of target achievement rate.

According to the statistics on Taobao crowdfunding platform, as of March 2019, there were 2,502 successful crowdfunding projects of design type, among which 11 were hot projects with achievement rate of more than $1,0000 \%, 267$ of $1,000 \%$ to $9999 \%$, and 2,222 of $100 \%$ to $999 \%$. ("Table VIII")

TABLE VIII. SUCCESS EVALUATION OF CROWDFUNDING PROJECTS

\begin{tabular}{|c|l|l|l|l|}
\hline Target achievement ratio & \multicolumn{1}{|c|}{ Over 10000\% } & \multicolumn{1}{|c|}{$\mathbf{1 0 0 0 \% - 9 9 9 9 \%}$} & \multicolumn{1}{|c|}{$\mathbf{1 0 0 \% - 9 9 9 \%}$} & \multicolumn{1}{c|}{ Less than 100\% } \\
\hline Number of projects & 11 & 267 & 2224 & - \\
\hline Proportion (\%) & 0.43 & 10.67 & 88.9 & - \\
\hline Success rating & Extremely successful & Very successful & successful & unsuccessful \\
\hline
\end{tabular}

Target achievement rate $X>10000 \%$, the project was very successful; $X>1000 \%$, the project was successful; $X>100 \%$, the project was successful. If the achievement rate $\mathrm{X}<70 \%$, the project may have some defect and need to be adjusted. 


\section{IMPLICATIONS}

\section{A. Giving cultural meaning is the eternal vitality of products}

Through Ma Jun[15] and other authors' research on the contribution of cultural and creative industry to GDP shows that the development of cultural and creative industry has promoted the rapid development of China's economy and the optimization and upgrading of industrial structure, this contribution is increasing year by year. In recent years, the scale of China's cultural industry has been constantly expanding, and the culture output has been continuously increasing, so there is still a large space for the development of cultural market. According to the report to the 18th national congress of the Communist Party of China, cultural and creative industry should be developed into a pillar industry of national economy by 2020 . At present, most popular cultural creation projects in the market are designed based on Chinese traditional culture. As a classic intellectual property inherited for thousands of years, the Palace Museum Taobao was warmly sought after by many consumers when it launched a series of original peripheral products ("Fig. 2 "). Unlike the solemnity of the Palace Museum in traditional impression, designers made the product closer to current mainstream aesthetics of young users by rejuvenating and trending Chinese style. And benefited from the promotion of the Internet and ecommerce platform, it quickly entered Inside young consumers and made many out of stock products. Thus it can be seen that traditional culture still has a certain appeal to consumers. Similarly, giving cultural meaning to products can also give them enduring vitality.

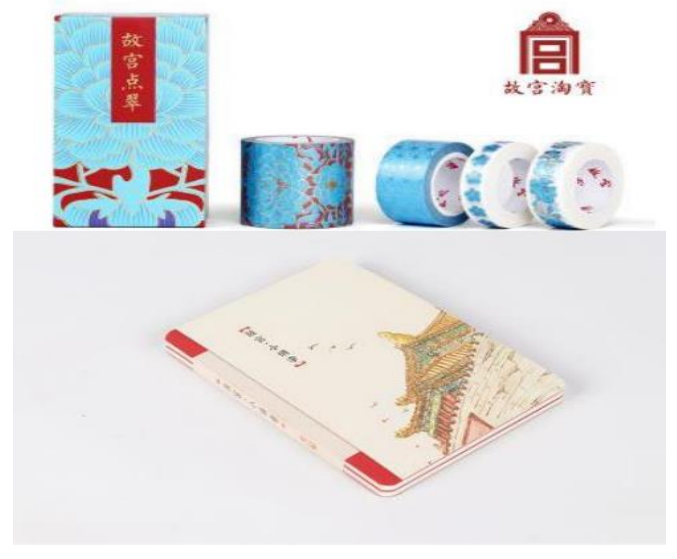

Fig. 2. Te Palace Museum Taobao series innovative products.

\section{B. Keeping up with new technology}

In the current classification of science and technology, most crowdfunding projects cover technological innovation. Based on the existing technology, through consideration of consumer' demand and pain points, the functions can be improved, and then products that meet higher market requirements can be launched. For example, the most popular air purifier is leading product iteration mainly by the innovation of its filtration and purification technology ("Fig. 3"). At present, the hottest negative ion purification technology can effectively reduce the harm of PM2.5 to hot bodies, which is leading another technological change in this field.

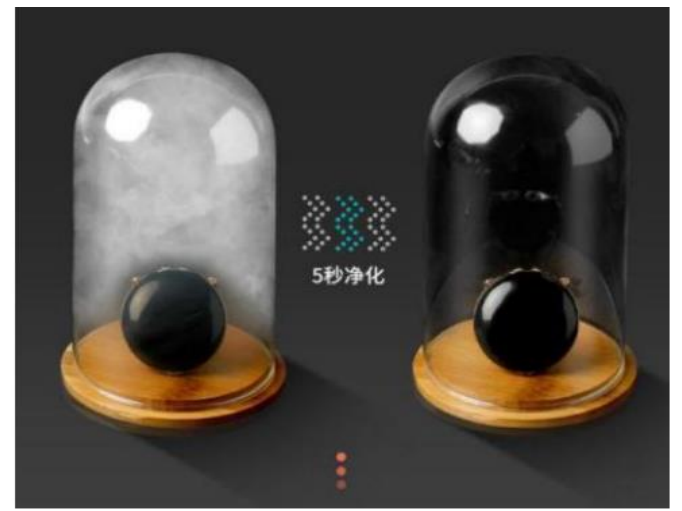

Fig. 3. Portable negative ion air purifier.

\section{Keeping up with new materials}

In addition to new technologies, new materials can also trigger a chain reaction in various industries after being put on the market. As a new material in recent years, graphene has been used in various fields. Products using graphene materials include massage health care ("Fig. 4"), hot compress physiotherapy, air purification, etc. Therefore, keeping a close eye on the market dynamics, following the development of the market, and paying more attention to frontier knowledge of CMF such as material changes, annual fashion colors, and latest surface treatment processes, all of these can contribute to grasp the market dynamics and seize the entrepreneurial opportunities.

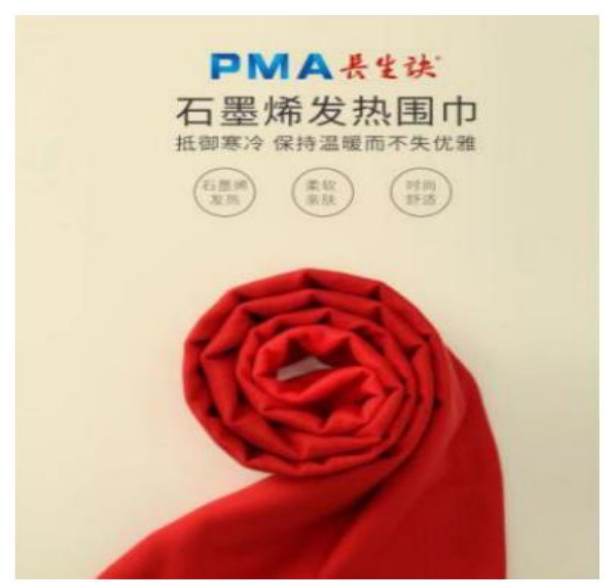

Fig. 4. Graphene health care products. 


\section{Application of new process}

Daily necessities are the most widely used products with the greatest market demand. Using new processes in products that are familiar to people to optimize them and improving using experience focus on users' pain points can often bring huge business opportunities. Taiwan brand Jemia ("Fig. 5"), which focuses on technology and craft research, has developed an antigravity shoulder strap, that are suitable for various types of backpacks. It can reduce the weight of backpacks through 3D air bags on the shoulder strap. This crowdfunding project was favored by many consumers after its launch, and eventually crowdfunding was successful with a rate of $1457 \%$. In addition, with the popularization of some technologies like 3d printing ("Fig. 6"), entrepreneurs have innovated this technology and skillfully applied it to digital peripheral market with large demand, such as mobile phone case, which won the recognition of many consumers by its novel product forms and preferential market prices.

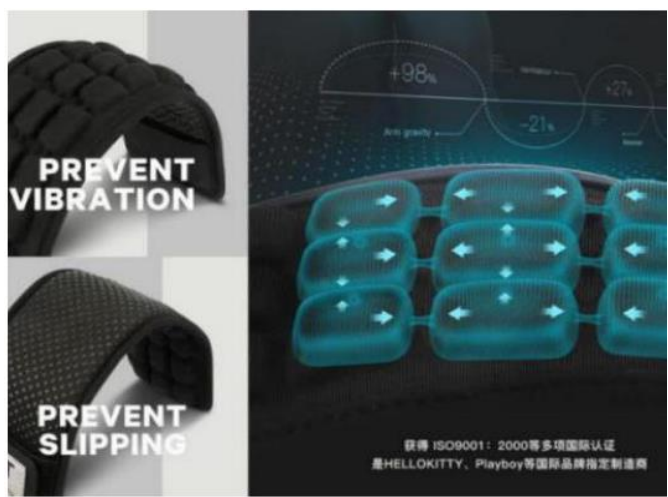

Fig. 5. Jamia weight loss shoulder strap.
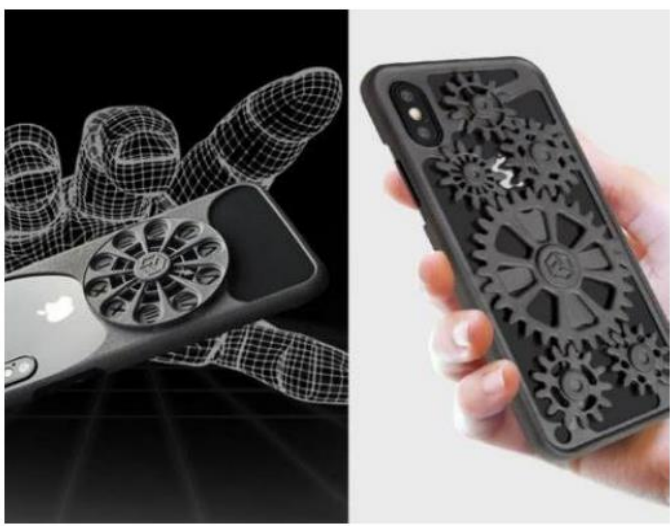

Fig. 6. 3D print phone case.

\section{CONCLUSION}

This paper is aimed at start-ups who are willing to innovate and start their own businesses. Based on above case analysis, features of existing successful entrepreneurial projects are extracted, which is of great significance to the identification of entrepreneurial opportunities for start-ups. Based on the project data on Taobao crowdfunding, Jingdong crowdfunding and other well-known crowdfunding platform, this article analyzes the distribution and direction of actual success cases, summarizes their success models and methods, and provides entrepreneurs with methods to identify opportunities. The article discusses the definition of project success and the indicators of success evaluation of crowdfunding projects, explores evaluation methods, and then provides a realistic reference for entrepreneurs.

\section{References}

[1] Guangdong, Hong Kong, Macao and Dawan District Development $\quad$ Planning Outline[EB/OL]. https://baike.baidu.com/ item/Guangdong,Hong Kong, Macao and Dawan District Development Planning Outline/22359240?fr=aladdin

[2] XIANG Le-duo. The 2018 China University Student Employment Report was released[EB/OL]. http://www.sohu. com/a/24185 0072_781087, 2018-07-18.

[3] MOLLICK E. The dynamics of crowdfunding:an exploratory study[J]. Journal of business venturing, 2014, 29 (1) :1-16.

[4] BELLEFLAMME P, OMRANI N, PEITZ M.The economics of crowdfunding platforms[J]. Information economic and policy, 2015 (33):11-28.

[5] HU Ji-xiang. Localized Innovation of Crowdfunding[J]. Securities Market Herald, 2014,(09), 4-10+15.

[6] GUAN Jian, Taobao crowds to raise the free banner: the innovator enters a door of Ali[N]. First Financial Daily, 2015, A11.

[7] JI Ling-yao, LI Lin-li, Deep integration of cultural creativity and related industries[J]. Journal of Southeast University, 2014,16(6).

[8] Taobao https://izhongchou.taobao.com/index.htm crowdfunding[EB/OL]

[9] SUN Ya-qing, Research on Resource Integration Mechanism of Cross-border Entrepreneurship Alliance[D]. Jilin: Jilin University, 2016.

[10] XU Lei, Boundary Spanning Behavior, Team Trust and Team Innovation Performance: Mediation Effect of Resource Depletion[J]. Science \& Technology Progress and Policy, 2019,36(06), 11-18.

[11] LV Qing-hua, A Review of the Literature of Geographic Factors of Internet Retailing from a Consumer Perspective[J].

[12] OISEN R P. Can project management be defined? [J]. Project Man-Agement Quarterly, 1969, 12(1): 77- 82

[13] BEDELL R J. Terminating R\& D Projects. Oxford: John Wiley \&Sons, 1987.

[14] BAKER B N, MURPHY D C, HOUGH G H. Factors affecting project success. NY: Project Management Journal, 1988, 19(1): 67-75.

[15] MA Jun, Research on the Impact of Cultural and Creative Industry Development on Economic Growth[J]. Statistics \& Decision, 2014. 20. 013 